\title{
The Use of Neuronavigation with Vasular Microdoppler in Transsphenoidal Pituitary Surgery
}

\author{
Mehmet Hakan Seyithanoglu${ }^{1}$, Serkan Kitis ${ }^{1 *}$, Meliha Gundag Papaker ${ }^{1}$, Fatih Calis ${ }^{1}$, \\ Tolga Turan Dundar ${ }^{1}$, Serdar Cevik ${ }^{2}$ \\ ${ }^{1}$ Department of Neurosurgery, Bezmialem Vakif University, Faculty of Medicine, Istanbul, Turkey \\ ${ }^{2}$ Department of Neurosurgery, Agri State Hospital, Agri, Turkey \\ Email: *serkankitis@yahoo.com, serkankitis@gmail.com
}

Received 17 December 2015; accepted 17 January 2016; published 20 January 2016

Copyright (C) 2016 by authors and Scientific Research Publishing Inc.

This work is licensed under the Creative Commons Attribution International License (CC BY). http://creativecommons.org/licenses/by/4.0/

c. (i) Open Access

\begin{abstract}
Object: To evaluate the use of neuronavigation with vascular micro-doppler in transsphenoidal pituitary surgery. Methods: 141 cases having done transsphenoidal pituitary surgery are evaluated from 2005 to 2014. Fluoroscopy was used in 69 cases and vascular micro-doppler with neuronavigation were used in 72 cases. Results: Transsphenoidal surgery has a lot of risks due to sella's deep location, and position of the carotid artery and the optic nerve. Clasically the fluoroscopy and microscopic anatomical markers were used in order to minimize the risk of carotid artery and optic nerve damage. Additional devices such as neuronavigation and vascular micro-doppler are needed to decrease the morbidity and mortality arising from these injuries. Conclusion: Neurovascular complications such as carotid artery and optic nerve injuries owing to disorientation in transsphenoidal surgery will reduce the use of neuronavigation with vascular micro-doppler.
\end{abstract}

\section{Keywords}

Transsphenoidal Surgery, Vascular Micro-Doppler, Neuronavigation, Pituitary Adenomas

\section{Introduction}

Pituitary adenoma is a benign neoplasm which is derived from adenohypophysis and grows slowly. Pituitary adenomas involve $10 \%$ of all intracranial tumors. Clinically pituitary adenomas are shown over secretion of hormone or mass effect. Classical surgical treatment of pituitary adenoma is a transsphenoidal approach. Transsphenoidal

${ }^{*}$ Corresponding author.

How to cite this paper: Seyithanoglu, M.H., Kitis, S., Papaker, M.G., Calis, F., Dundar, T.T. and Cevik, S. (2016) The Use of Neuronavigation with Vasular Microdoppler in Transsphenoidal Pituitary Surgery. Open Journal of Modern Neurosurgery, 6, 45-50. http://dx.doi.org/10.4236/ojmn.2016.61009 
surgery is a safe and effective procedure which has mortality and morbidity less than 1\% [1]-[6]. The most serious complication of this surgery is cavernous internal carotid artery injury during the dural incision in sellar base. This catastrophic complication is seen in $0.3 \%-8 \%$ of cases [7]-[16]. Optic nerve injury is another complication of this surgery. Generally fluoroscopy and microscope are used in these operations. Surgeons have disorientation during transsphenoidal surgery due to anatomic variation of the patient and fluoroscopy gives sagittal series of images [8]. Intraoperative Computerized Tomography and Magnetic Resonance have some difficulties in relation to the working comfort of the surgeon owing to occupy a place in operating room. Frameless neuronavigation devices provide for midline and 3-D orientation. Additionally micro-doppler usage before dural incision, carotid localization is determined and potential injuries of Internal carotid artery (ICA) can be avoided [17] [18].

\section{Methods}

141 patients were evaluated retrospectively between 2005 January and 2014 June. All patients had operated by the same surgent and signed informed consent before surgery. Classical fluoroscopy was used in 69 patients (48.9\%) and neuronavigation with vascular micro-doppler used in 72 patients (51.1\%). Two of the patients which we used only fluoroscopy had internal carotid artery injury; one during dural incision and the other during resection of septum nasi. There are no other vascular injuries in these series.

The range of the patients is 6 - 78 years (mean 45.21 std. Deviatiotion 14.894). 3 of the patients had craniopharengioma and 138 of them with hypophysis tumour. Of 138 patients, 54 had high Growth hormone levels whereas 23 had high Adrenocorticotropic hormone, 24 had high Thyroid-stimulating hormone, 6 had prolactinoma and 31 had non-function pituitary adenomas (Table 1). 104 of the patients operated for the first time (73.8\%), 37 of patients had had one or more operation previously (26.2\%). This study doesn't include the relapse of first operated patients. Standard transnasal transsphenoidal surgery was applied for all patients.

Neuronavigation (Medtronic, Minneapolis, ABD) with mach version 4.01 programme used in 72 patients instead of fluoroscopy (Figure 1). Computerized Tomography (CT) navigation has done 24 - 48 hours before surgery. The presentation of patients to neuronavigation device was done by means of anatomic landmarks [19]. After record, the error margin of all patients was below the $2 \mathrm{~mm}$. This is accepted as safety border [20].

Micro-doppler probe was used (20-Mhz surgical Doppler/Nashua, America) to establish cavernous ICA before dural incision in 72 patients. The micro-doppler has 2 to $2.5 \mathrm{~mm}$ diameter, insonation angle has 0-degree and $1 \times 1 \mathrm{~mm}$ beam width (Figure 2). Firstly the navigation probe is placed with 90 degrees to the dura (Figure 3). After that micro-doppler probe is placed and if flow is insignificant, the micro-probe is angled laterally. Then, in order to determine the ICA localization the micro-doppler moved superiorly and inferiorly. If micro-doppler flow is absent, extra bone removed to extended sellar exposure. Neuronavigation with microdoppler were used in the course of dural incision in sellar base and enlargement of dura in 72 patients. Tumour resection and repairing of bone defect were made with standard technique [6] [21]. Obtained data were analyzed using SPSS $17.00 \circledR$ software.

\section{Results}

Transnasal transsphenoidal surgery was performed on 141 patients during 2005 January-2014 June (77 female, 64 male, age range: 6 - 78 years, mean: 45.21 ). 104 of patients (73.8\%) operated for the first time, 37 of patients (26.2\%) had one or more operation previously. 7 patients had Cerebrospinal fluid (CSF) fistulas (5\%), 2 patients

Table 1. Pathological diagnoses of 141 patients undergoing transsphenoidal surgery.

\begin{tabular}{cc}
\hline Patholology & No of Patients \\
\hline Pituitary adenoma & 138 \\
Endocrine inactive & 31 \\
ACTH secreting & 23 \\
Prolactinoma & 6 \\
GH secreting & 54 \\
TSH secreting & 24 \\
Craniopharyngioma & 3 \\
\hline
\end{tabular}




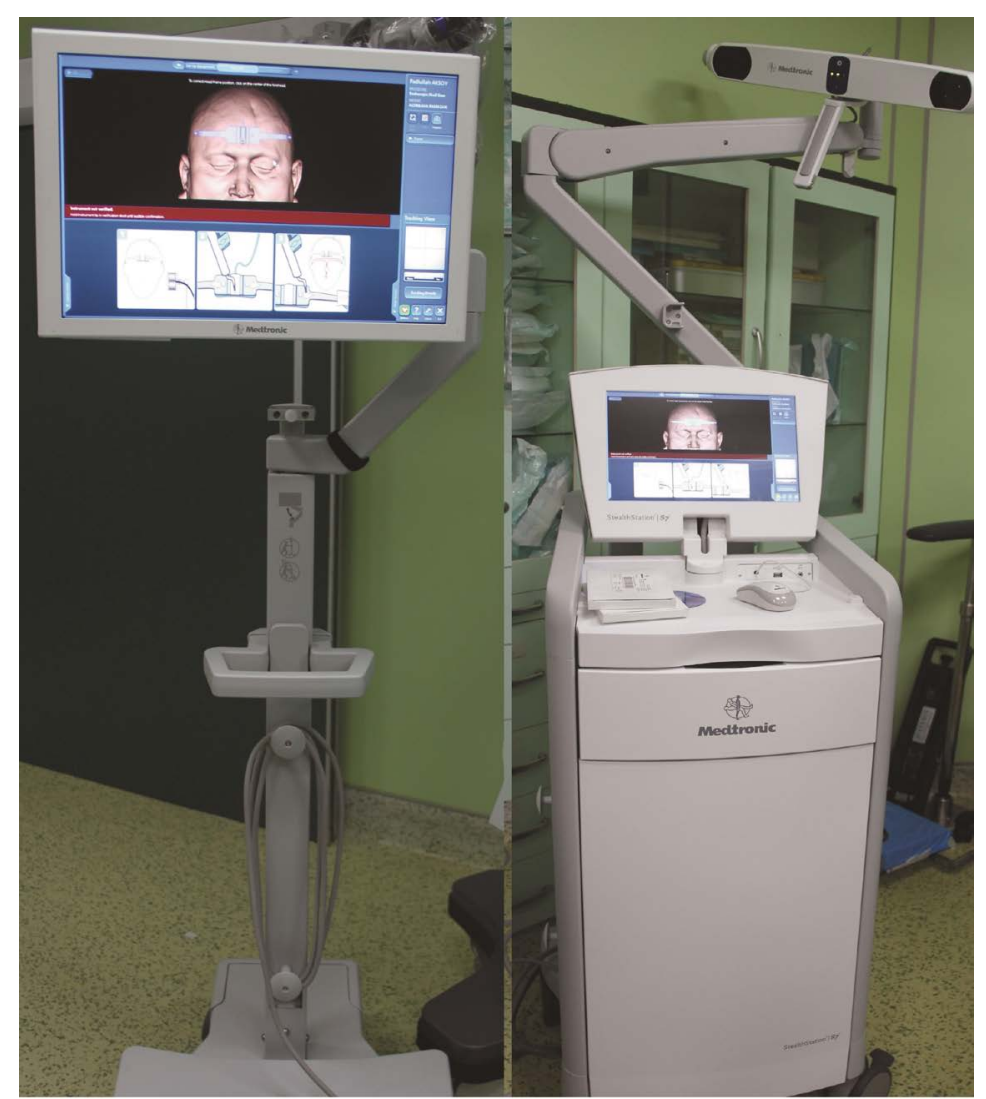

Figure 1. Neuronavigation system.

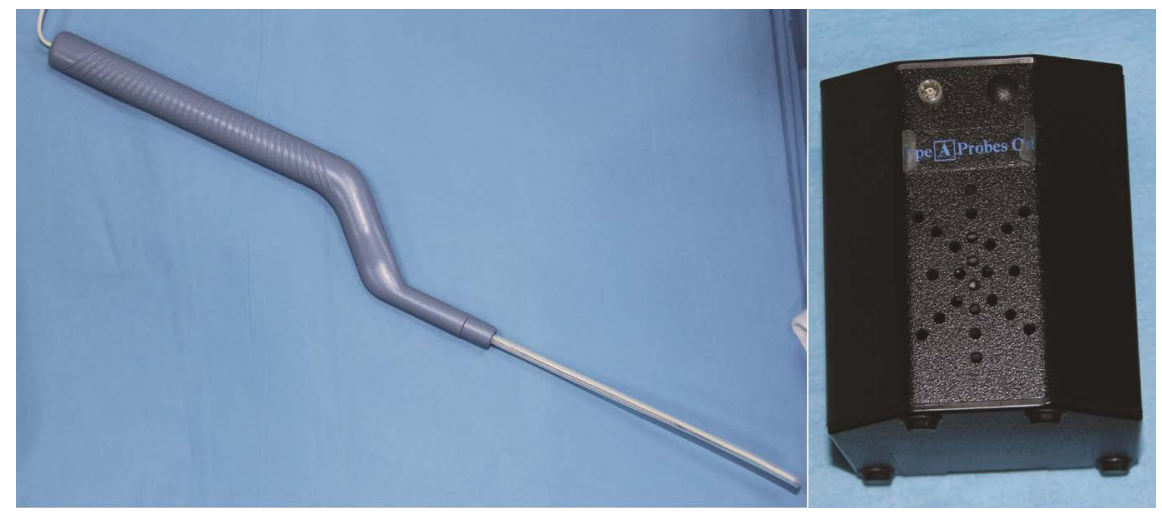

Figure 2. Micro-doppler probe.

had internal carotis artery injury (1.4\%) and one of the patients had optic nerve injury (0.7\%) in fluoroscopy group. CSF fistulas have stopped a few days after spinal drainage. First patient who had carotis injury is a 57year-old male. The bleeding was mended via collagen sponge, abdominal fat, and tissue glue. ICA was seen intact in post-operative carotis angiography. Neurologic examination of patient was normal and tumor was controlled with stereotactic radiosurgery. Second patient who had carotis injury is a 40-year-old female during dural incision Left ICA hemorrhage occured. The bleeding was mended via collagen sponge, abdominal fat, and tissue glue. Thinning of anterior wall in anterior folding of internal carotis artery was seen in postoperative cranial angiography. Defect was repaired with endovascular detechable coil. Neurologic examination of patient was normal and tumour was controlled with stereotactic radiosurgery. A 54-year-old man in fluoroscopy group had left optic nerve injury during removal of sphenoid septum. The patient had left eye vision loss postoperatively. 


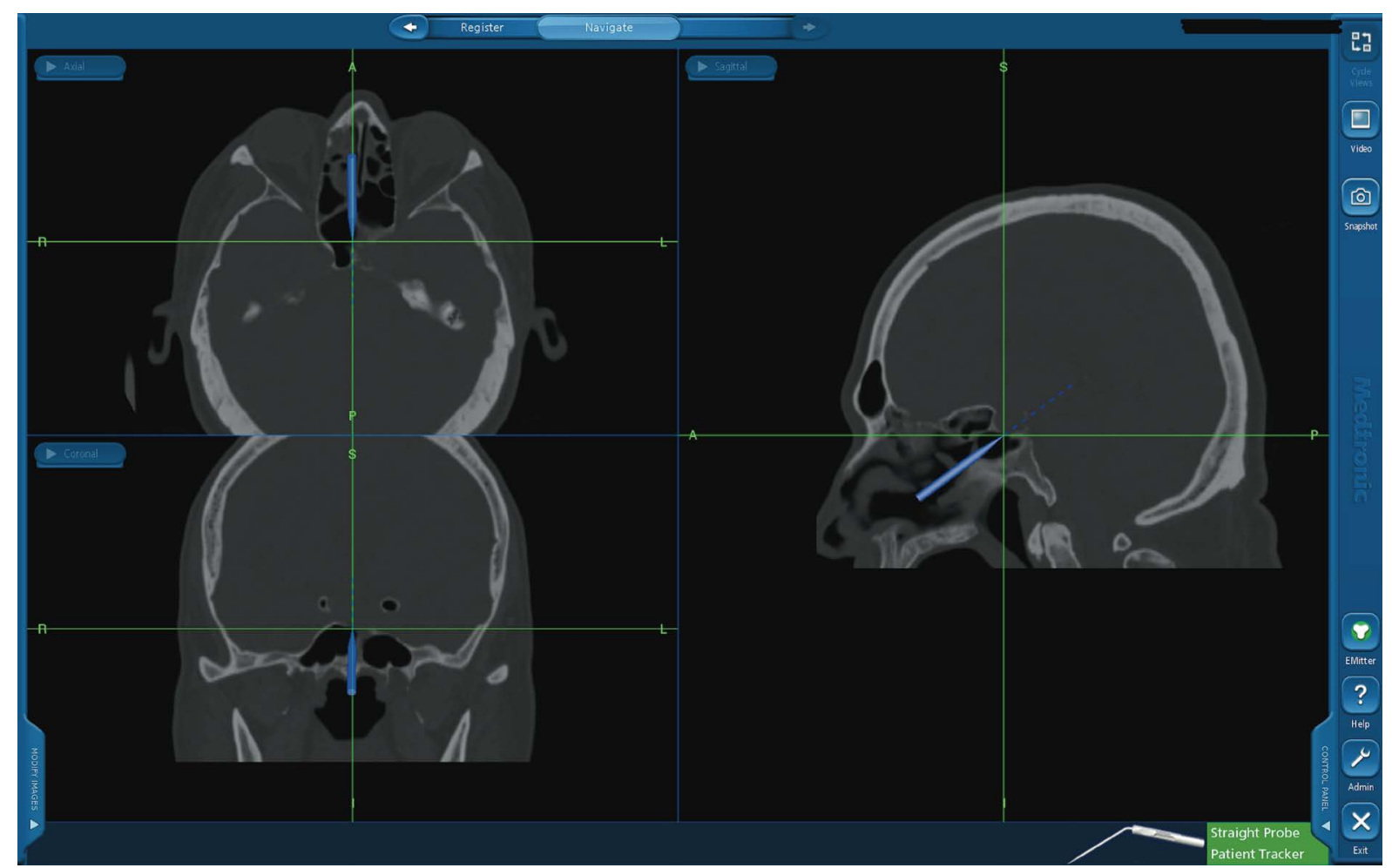

Figure 3. Neuronavigation give images in sagittal, coronal and axial plane and remove the midline deviation problem of surgeon.

There were no vascular or neural complications in the group in which we used neuronavigation with microdoppler.

\section{Discussion}

Transsphenoidal surgery is the most preferred method in pituitary adenomas' disadvantages of transsphenoidal approaches are sella's deeply location, adjacent of carotid artery and 2 dimentions images with flouroscopy [1] [22] [23]. On the other hand 3-D images with neuronavigation make surgery easier.

Although complication rates decrease with time, anatomical disorientation is the reason for $56.4 \%$ of complications. Fluoroscopy gives only sagittal image and this is insufficient to determine the midline. The most important determiner is anatomical landmmarks. Anatomical variations in some patients can cause a deviation from midline and catastrophic results occured because of vascular and neural injuries. The $2 \mathrm{~d}$ dimension course of the fluoroscopy leads misplacement and thus deviation from midline to the left side.

Neuronavigation give images in sagittal, coronal and axial plane and remove the anatomical disorientation (Figure 3). In addition differentiation between tumour and normal anatomy is seen very well therefore the important structures' injuries are decreased and totally tumour resection possibility is increased [22]. Furthermore during tumour resection, neurovascular structures shiftis occurred. Neuronavigation integrated with micro-doppler supply real time images and resolve the brain shift problem [24]-[27].

There are many case reports in literatures related to transsphenoidal surgery such as; fatal haemorrhage, ICA pseudoaneurysm, caroticocavernous fistula, vasospasm and infarct with embolus [12] [13] [15] [16] [28]-[30]. Carotis injury is in the range of $0 \%-3 \%$ in large series [1] [2] [7]-[10].

Because of removes radiation exposure, decreases in operation time and neurovascular complications and increases of amount of tumor resection neuronavigation and micro-doppler are advised [20] [26] [31]-[33].

In despite of Kitano and Taneda advice to use microdoppler for intracavernous carotis artery determination before dural incision during intracavernous tumour resection, previous literature does not use microdoppler routinely [34].

Dusick and friends have asserted in a study with more than 500 patients, the usage of microdoppler before 
dural incision decreases risk of ICA injury [35]. This noninvasive method takes 2 to 3 minutes; moreover dural opening for cavernous sinus, suprasellar, and retroclival lesions provides extended approaches so the Internal Carotid Artery and other neurovascular tissues are ptotected. Microdoppler gives real time voice in all pulsation and exact knowledge about artery localization [35]. For this reason neuronavigation with micro-doppler usage are increases safety about neurovascular structures.

\section{Conclusion}

Neuronavigation with micro-doppler usage has some advantages, such as to increase anatomical orientation especially in recurrent transsphenoidal surgery, to increase to protect neurovascular tissues, and to decrease the radiation exposure and operation time. The disadvantages of neuronavigation's application in transsphenoidal surgery were expensive technique and limited neurosurgical department. Consequently, we strongly advise neuronavigation with micro-doppler in transsphenoidal surgery.

\section{References}

[1] Black, P.M., Zervas, N.T. and Candia, G.L. (1987) Incidence and Management of Complications of Transsphenoidal Operation for Pituitary Adenomas. Neurosurgery, 20, 920-924. http://dx.doi.org/10.1227/00006123-198706000-00017

[2] Cappabianca, P., Cavallo, L.M., Colao, A. and de Divitiis, E. (2002) Surgical Complications Associated with the Endoscopic Endonasal Transsphenoidal Approach for Pituitary Adenomas. Journal of Neurosurgery, 97, 293-298. http://dx.doi.org/10.3171/jns.2002.97.2.0293

[3] Dusick, J.R., Esposito, F., Mattozo, C.A., Chaloner, C., McArthur, D.L. and Kelly, D.F. (2006) Endonasal Transsphenoidal Surgery: The Patient’s Perspective-Survey Results from 259 Patients. Surgical Neurology, 65, 332-342. http://dx.doi.org/10.1016/j.surneu.2005.12.010

[4] Laws Jr., E.R. and Thapar, K. (1999) Pituitary Surgery. Endocrinology and Metabolism Clinics of North America, 28, 119-131. http://dx.doi.org/10.1016/S0889-8529(05)70059-1

[5] Liu, J.K., Das, K., Weiss, M.H., Laws Jr., E.R. and Couldwell, W.T. (2001) The History and Evolution of Transsphenoidal Surgery. Journal of Neurosurgery, 95, 1083-1096. http://dx.doi.org/10.3171/jns.2001.95.6.1083

[6] Zada, G., Kelly, D.F., Cohan, P., Wang, C. and Swerdloff, R. (2003) Endonasal Transsphenoidal Approach for Pituitary Adenomas and Other Sellar Lesions: An Assessment of Efficacy, Safety, and Patient Impressions. Journal of Neurosurgery, 98, 350-358. http://dx.doi.org/10.3171/jns.2003.98.2.0350

[7] Cavallo, L.M., Briganti, F., Cappabianca, P., Maiuri, F., Valente, V., Tortora, F., Volpe, A., Messina, A., Elefante, A. and de Divitiis, E. (2004) Hemorrhagic Vascular Complications of Endoscopic Transsphenoidal Surgery. Minimally Invasive Neurosurgery, 47, 145-150. http://dx.doi.org/10.1055/s-2004-818489

[8] Ciric, I., Ragin, A., Baumgartner, C. and Pierce, D. (1997) Complications of Transsphenoidal Surgery: Results of a National Survey, Review of the Literature, and Personal Experience. Neurosurgery, 40, 225-237. http://dx.doi.org/10.1097/00006123-199702000-00001

[9] Couldwell, W.T., Weiss, M.H., Rabb, C., Liu, J.K., Apfelbaum, R.I. and Fukushima, T. (2004) Variations on the Standard Transsphenoidal Approach to the Sellar Region, with Emphasis on the Extended Approaches and Parasellar Approaches: Surgical Experience in 105 Cases. Neurosurgery, 55, 539-550. http://dx.doi.org/10.1227/01.NEU.0000134287.19377.A2

[10] Fukushima, T. and Maroon, J.C. (1998) Repair of Carotid Artery Perforations during Transsphenoidal Surgery. Surgical Neurology, 50, 174-177. http://dx.doi.org/10.1016/S0090-3019(96)00416-8

[11] Inamasu, J. and Guiot, B.H. (2005) Iatrogenic Carotid Artery Injury in Neurosurgery. Neurosurgical Review, 28, 239248. http://dx.doi.org/10.1007/s10143-005-0412-7

[12] Kocer, N., Kizilkilic, O., Albayram, S., Adaletli, I., Kantarci, F. and Islak, C. (2002) Treatment of Iatrogenic Internal Carotid Artery Laceration and Carotid Cavernous Fistula with Endovascular Stent-Graft Placement. AJNR American Journal of Neuroradiology, 23, 442-446.

[13] Laws Jr., E.R. (1999) Vascular Complications of Transsphenoidal Surgery. Pituitary, 2, 163-170. http://dx.doi.org/10.1023/A:1009951917649

[14] Mortini, P., Losa, M., Barzaghi, R., Boari, N. and Giovanelli, M. (2005) Results of Transsphenoidal Surgery in a Large Series of Patients with Pituitary Adenoma. Neurosurgery, 56, 1222-1233. http://dx.doi.org/10.1227/01.NEU.0000159647.64275.9D

[15] Oskouian, R.J., Kelly, D.F. and Laws Jr., E.R. (2006) Vascular Injury and Transsphenoidal Surgery. Frontiers of Hormone Research, 34, 256-278. http://dx.doi.org/10.1159/000091586 
[16] Raymond, J., Hardy, J., Czepko, R. and Roy, D. (1997) Arterial Injuries in Transsphenoidal Surgery for Pituitary Adenoma, the Role of Angiography and Endovascular Treatment. AJNR American Journal of Neuroradiology, 18, 655-665.

[17] Yamasaki, T., Moritake, K., Hatta, J. and Nagai, H. (1996) Intraoperative Monitoring with Pulse Doppler Ultrasonography in Transsphenoidal Surgery: Technique Application. Neurosurgery, 38, 95-98. http://dx.doi.org/10.1097/00006123-199601000-00022

[18] Yamasaki, T., Moritake, K., Nagai, H. and Kimura, Y. (2002) Integration of Ultrasonography and Endoscopy into Transsphenoidal Surgery with a "Picture-in-Picture" Viewing System-Technical Note. Neurologia Medico-Chirurgica (Tokyo), 42, 275-278. http://dx.doi.org/10.2176/nmc.42.275

[19] Wolfsberger, S., Rössler, K., Regatschnig, R. and Ungersböck, K. (2002) Anatomical Landmarks for Image Registration in Frameless Stereotactic Neuronavigation. Neurosurgical Review, 25, 68-72. http://dx.doi.org/10.1007/s10143-001-0201-x

[20] Walker, D., Ohaegbulam, C. and Black, P. (2002) Frameless Stereotaxy as an Alternative to Fluoroscopy for Transsphenoidal Surgery: Use of the Insatrak-3000 and a Novel Headset. Journal of Clinical Neuroscience, 9, $294-297$. http://dx.doi.org/10.1054/jocn.2001.0964

[21] Kelly, D.F., Oskouian, R.J. and Fineman, I. (2001) Collagen Sponge Repair of Small Cerebrospinal Fluid Leaks Obviates Tissue Grafts and Cerebrospinal Fluid Diversion after Pituitary Surgery. Neurosurgery, 49, 885-890.

[22] Fahlbusch, R. and Buchfelder, M. (1988) Transsphenoidal Surgery of Parasellar Pituitary Adenomas. Acta Neurochirurgica, 92, 93-99. http://dx.doi.org/10.1007/BF01401978

[23] Watanabe, E., Watanabe, T. and Manaka, S. (1987) Three-Dimensional Digitizer (Neuronavigator): New Equipment for CT-Guided Stereotactic Surgery. Surgical Neurology, 27, 543-547. http://dx.doi.org/10.1016/0090-3019(87)90152-2

[24] Brinker, T., Arango, G., Kaminsky, J., Samii, A., Thorns, U., Vorkapic, P. and Samii, M. (1998) An Experimental Approach to Image Guided Skull Base Surgery Employing a Microscope-Based Neuronavigation System. Acta Neurochirurgica, 140, 883-889. http://dx.doi.org/10.1007/s007010050189

[25] Koivukangas, J., Louhisalmi, Y., Alakuijala, J. and Oikarinen, J. (1993) Ultrasound-Controlled Neuronavigator-Guided Brain Surgery. Journal of Neurosurgery, 79, 36-43. http://dx.doi.org/10.3171/jns.1993.79.1.0036

[26] Sandeman, D. and Moufid, A. (1998) Interactive Image-Guided Pituitary Surgery: An Experience of 101 Procedures. Neurochirurgie, 44, 331-338.

[27] Unsgaard, G., Ommedal, S., Muller, T., Gronningsaeter, A. and Nagelhus, H. (2002) Neuronavigation by Intraoperative Threedimensional Ultrasound: Initial Experience during Brain Tumor Resection. Neurosurgery, 50, 804-812. http://dx.doi.org/10.1097/00006123-200204000-00022

[28] Elias, W.J., Chadduck, J.B., Alden, T.D. and Laws, E.R. (1999) Frameless Stereotaxy for Transsphenoidal Surgery. Neurosurgery, 45, 271-277. http://dx.doi.org/10.1097/00006123-199908000-00015

[29] Hardy, J. (1999) Neuronavigation in Pituitary Surgery. Surgical Neurology, 52, 648-649. http://dx.doi.org/10.1016/S0090-3019(99)00152-4

[30] Kim, S.H., Shin, Y.S., Yoon, P.H. and Kim, D.I. (2002) Emergency Endovascular Treatment of Internal Carotid Artery Injury during a Transsphenoidal Approach for a Pituitary Tumor: Case Report. Yonsei Medical Journal, 43, 119-122. http://dx.doi.org/10.3349/ymj.2002.43.1.119

[31] Cappabianca, P., Briganti, F., Cavallo, L.M. and de Divitiis, E. (2001) Pseudoaneurysm of the Intracavernous Carotid Artery Following Endoscopic Endonasal Transsphenoidal Surgery, Treated by Endovascular Approach. Acta Neurochirurgica, 143, 95-96. http://dx.doi.org/10.1007/s007010170144

[32] Kadyrov, N.A., Friedman, J.A., Nichols, D.A., Cohen-Gadol, A.A., Link, M.J. and Piepgras, D.G. (2002) Endovascular Treatment of an Internal Carotid Artery Pseudoaneurysm Following Transsphenoidal Surgery. Case Report. Journal of Neurosurgery, 96, 624-627. http://dx.doi.org/10.3171/jns.2002.96.3.0624

[33] Ohhashi, G., Kamio, M., Abe, T., Otori, N. and Haruna, S. (2001) Endoscopic Transnasal Approach to the Pituitary Lesions Using Navigation System (InsaTrak System). Acta Neurochirurgica, 143, 501-504. http://dx.doi.org/10.1007/s007010170080

[34] Kitano, M. and Taneda, M. (2001) Extended Transsphenoidal Approach with Submucosal Posterior Ethmoidectomy for Parasellar Tumors. Technical Note. Journal of Neurosurgery, 94, 999-1004. http://dx.doi.org/10.3171/jns.2001.94.6.0999

[35] Dusick, J.R., Esposito, F., Malkasian, D. and Kelly, D.F. (2007) Avoidance of Carotid Artery Injuries in Transsphenoidal Surgery with the Doppler Probe and Micro-Hookblades. Operative Neurosurgery, 60, 322-328. http://dx.doi.org/10.1227/01.NEU.0000255408.84269.A8 